\title{
ANTICIPATING OF CHAOTIC STATES VIA ANTI-PHASE DIAGONAL COUPLING
}

\author{
T. Pyragienė and K. Pyragas \\ Semiconductor Physics Institute, Center for Physical Sciences and Technology, A. Goštauto 11, LT-01108 Vilnius, Lithuania \\ E-mail: pyragiene@pfi.lt
}

Received 17 March 2010; accepted 17 June 2010

\begin{abstract}
Anticipating synchronization is considered as a tool for a real-time forecasting of chaotic dynamics. An anti-phase diagonal coupling scheme is introduced in order to supply the long-term prediction of behaviour of a drive system. The efficiency of such a scheme is studied analytically using a simple model of unstable spiral and justified numerically for two unidirectionally coupled chaotic Rössler systems. The maximum prediction time attained with our algorithm equals to the half of characteristic period of chaotic oscillations.
\end{abstract}

Keywords: synchronization, delay, anticipating of chaos

PACS: 05.45.Xt, 05.45.Gg, 02.30.Yy

\section{Introduction}

Long ago the notion of chaos was associated with the devoid of structure, absolutely uncontrollable and unpredictable state or process [1]. In the end of 1980s the things have been changed due to the progress in computer technology: the qualitative measures of order for the chaotic system were introduced (e. g., Lyapunov exponents) and classical control of dynamical systems turned into chaos control area [2]. Finally, in 2000, a way of forecasting of chaotic dynamics was introduced by Voss [3]. The proposed method relies on the phenomenon of anticipating synchronization.

The phenomenon of synchronization refers to the collective timing of coupled systems and manifests itself in physical, chemical, as well as biological systems [4]. Recently the notion of synchronization was generalized and applied to different chaotic systems [511]. Anticipating synchronization refers to a particular regime, which appears in unidirectionally coupled systems in a master-slave configuration. In this regime, two dynamical systems synchronize in such a way that the slave system anticipates the trajectory of the master. Anticipating synchronization has been studied theoretically and experimentally in many systems, e.g., in chaotic semiconductor lasers [12-14], in electronic circuits [15], in excitable systems [16], in coupled inertial ratchets [17], and in neural networks $[18,19]$. It is remarkable that neither nonlinearity nor chaotic dynamics of the master and drive systems are the necessary condition for the anticipating synchronization [20].

Two principal schemes have been proposed in order to achieve anticipated synchronization. Both schemes use delay lines which allow forecasting of a master trajectory by a slave identical system. The first scheme implies the presence of delay in the master system and uses the technique of complete replacement [3]:

$$
\begin{aligned}
& \dot{\mathbf{r}}_{1}(t)=-\alpha \mathbf{r}_{1}(t)+\mathbf{f}\left(\mathbf{r}_{1}(t-\tau)\right), \\
& \dot{\mathbf{r}}_{2}(t)=-\alpha \mathbf{r}_{2}(t)+\mathbf{f}\left(\mathbf{r}_{1}(t)\right),
\end{aligned}
$$

where $\alpha>0$ is a constant, $\mathbf{f}(\mathbf{r})$ is a function which defines the autonomous dynamical system under consideration, and $\tau$ is the delay time. The first equation describes the behaviour of the master system and another manages the evolution of the slave system. The second scheme, delay coupling [21], is one that does not imply the presence of delay in the master system and includes only a delay in the slave dynamics:

$$
\begin{aligned}
& \dot{\mathbf{r}}_{1}(t)=\mathbf{f}\left(\mathbf{r}_{1}(t)\right), \\
& \dot{\mathbf{r}}_{2}(t)=\mathbf{f}\left(\mathbf{r}_{2}(t)\right)+\mathbf{K}\left[\mathbf{r}_{1}(t)-\mathbf{r}_{2}(t-\tau)\right],
\end{aligned}
$$

where $\mathbf{K}$ is a coupling strength matrix. It is easy to see that in both schemes the manifold $\mathbf{r}_{2}(t)=\mathbf{r}_{1}(t+\tau)$ is a solution of the equations, i. e., the slave anticipates by an amount $\tau$ the output of the master. In the first case, 
Eqs. (1), the anticipated solution is globally stable independent of both function $\mathbf{f}(\mathbf{r})$ and the arbitrarily large delay time $\tau$ [3]. Delay coupling scheme, Eqs. (2), deserves more attention than that of complete replacement despite the fact that it requires some constraints on the anticipation time $\tau$ and coupling $\mathbf{K}$ for the synchronization solution to be stable [20,21]. This is because the anticipating time $\tau$ is included as an external parameter and does not influence the dynamics of the master system. In principle, any dynamical system can be predicted by using this scheme [18].

Naturally, one attends to construct the coupling schemes with a possibly large anticipation time. The analysis of the scheme (2b) with a diagonal matrix $\mathbf{K}$ shows that it is ineffective [3]. Its maximum stably anticipation time is much shorter than the characteristic time scales of the system's dynamics. Then Voss [21] proposed to extend Eq. (2b) with a chain of $N$ unidirectionally coupled slave systems

$$
\begin{gathered}
\dot{\mathbf{r}}_{i}(t)=\mathbf{f}\left(\mathbf{r}_{i}(t)\right)+k \mathbf{K}\left[\mathbf{r}_{i-1}(t)-\mathbf{r}_{i}(t-\tau)\right], \\
i=2, \ldots, N+1 .
\end{gathered}
$$

Formally, the prediction time of this scheme is $N$ times larger as compared to the scheme described by Eqs. (2). However, more recently it has been shown that the chain is unstable to propagating perturbations [22].

In our recent publication [23], we considered the single-slave scheme with coupled Rössler-like [24] chaotic systems. We proposed an algorithm of the design of the matrix $\mathbf{K}$ based on a phase-lag compensating coupling (PLCC). We took into account the peculiarity of a topology of the Rössler system [24] and introduced a coupling matrix that projects the vector field onto the unstable spiral manifold and rotates this projection by the angle $\alpha=\omega \tau$. Here $\omega$ is a frequency of the unstable spiral. The advantage of this choice is in providing a stabilizing negative feedback. In this paper we suggest the way to simplify the experimental implementation of the PLCC method. We study the case of $\alpha=\pi$, i. e., an anti-phase diagonal coupling (APDC) scheme. First, we consider the simple model of two identical spirals with delayed unidirectional coupling. Obtained results enable us to estimate the optimal values of the control gain and the largest prediction time. Then we deal with two identical chaotic systems and perform numerical calculations to justify the anticipating synchronization in unidirectionally coupled Rössler systems with the anti-phase diagonal coupling scheme and with anti-phase coupling only in one dynamical variable. It is shown that prediction time attained by the APDC scheme is equal to the half of characteristic period of chaotic oscillations.

\section{Analytical treatment for the coupled spirals}

When analysing the anticipating synchronization it is usual to study simplified models describing the essential features of system's behaviour (e.g., [16]). A simplified dynamical model we have used to imitate the essential properties of the Rössler system is described by two linear equations: $\dot{x}=\gamma x-\omega y$ and $\dot{y}=\omega x+\gamma y$, which define an unstable spiral with positive increment $\gamma$ and frequency $\omega$ [23]. For the complex variable $z=x+\mathrm{i} y$, this system can be presented by a simple equation $\dot{z}=(\gamma+\mathrm{i} \omega) z$. Then equations for anticipating synchronization of two spirals take the form

$$
\begin{aligned}
& \dot{z}_{\mathrm{d}}=(\gamma+\mathrm{i} \omega) z_{\mathrm{d}}, \\
& \dot{z}=(\gamma+\mathrm{i} \omega) z-k\left[z_{\mathrm{d}}-z(t-\tau)\right] .
\end{aligned}
$$

Here $z_{\mathrm{d}}(t)$ and $z(t)$ are the complex amplitudes in the point of time $t$. The dynamical variable $z_{\mathrm{d}}$ characterizes the drive (master) system described by Eq. (4a). The response (slave) system described by Eq. (4b) is connected to the first one via the anti-phase delayed coupling $-k\left[z_{\mathrm{d}}-z(t-\tau)\right]$. The solution of the drive system (4a) is

$$
z_{\mathrm{d}}(t)=\mathrm{e}^{(\gamma+\mathrm{i} \omega) t} .
$$

It is easy to see that the anticipating synchronization manifold $z_{\mathrm{d}}(t+\tau)=z(t)$ is a solution of the equations. However, the delay coupling scheme requires some constraints on the anticipation time $\tau$ and coupling strength $k$ for the synchronization solution to be stable [21]. That is why we proceed with the analytical treatment of the system stability. First, we introduce the deviation

$$
\Delta(t)=z(t)-z_{\mathrm{d}}(t+\tau)
$$

and obtain the dynamical equation for it

$$
\dot{\Delta}=(\gamma+\mathrm{i} \omega) \Delta+k \Delta(t-\tau) .
$$

Looking for a solution of Eq. (7) in a form of

$$
\Delta=\mathrm{e}^{(\lambda+\mathrm{i} \omega) t}
$$

we obtain the characteristic equation

$$
(\lambda-\gamma) \mathrm{e}^{\lambda \tau}-k \mathrm{e}^{-\mathrm{i} \omega \tau}=0 .
$$

Taking $W(y)=\tau(\lambda-\gamma)$ with $y=k \tau \mathrm{e}^{-\gamma \tau} \mathrm{e}^{-\mathrm{i} \omega \tau}$, we see that function $W(y)$ satisfies the definition of 


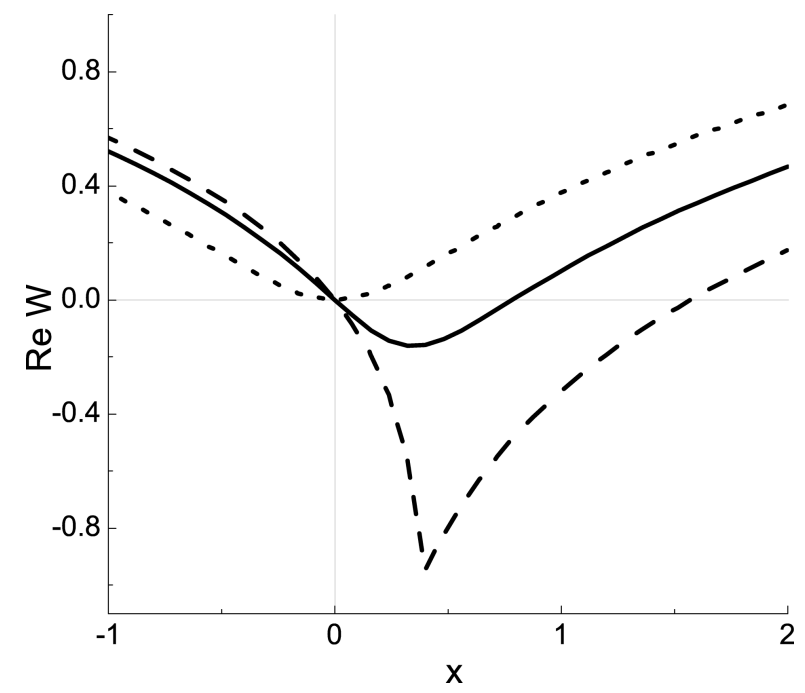

Fig. 1. The dependence $\operatorname{Re}\left[W\left(x \mathrm{e}^{\mathrm{i} \varphi}\right)\right]$ versus $x$ for the cases: $\varphi=$ $\pi / 2$ (dot line), $\pi / 2<\varphi<3 \pi / 2$ (solid line), and $\varphi=3 \pi / 2$ (dash line). Here $\varphi=\omega \tau, \omega$ is the frequency of the spiral, and $\tau$ is the prediction time.

the Lambert function: $W(y) \mathrm{e}^{W(y)}=y$ [25]. Hence, the solution of the characteristic equation (9) can be expressed through the Lambert function:

$$
\lambda=\gamma+\frac{W\left(k \tau \mathrm{e}^{-(\gamma \tau+\mathrm{i} \omega \tau)}\right)}{\tau} .
$$

Now we are interesting in the stability of the synchronization regime and its boundaries on the system's parameter plane. Synchronization regime is stabile only when

$$
\operatorname{Re}[\lambda(k)]<0 .
$$

Taking into account the expression (10) for the eigenvalues, at first we analyse when the condition

$$
\operatorname{Re}\left[W\left(x \mathrm{e}^{-\mathrm{i} \omega \tau}\right)\right]<0 \quad\left(x=k \tau \mathrm{e}^{-\gamma \tau}>0\right)
$$

is satisfied. The character of behaviour of the function $\operatorname{Re}\left[W\left(x \mathrm{e}^{-\mathrm{i} \omega \tau}\right)\right]$ depends on the prediction time $\tau$ as demonstrated in Fig. 1. We see that the condition (12) is satisfied when

$$
\frac{\pi}{2 \omega}<\tau<\frac{3 \pi}{2 \omega} .
$$

In order to find the synchronization ranges, i. e., the values of the control parameter $k$ satisfying $\operatorname{Re}[\lambda(k)]=0$, we substitute $\lambda=i \Omega$ in Eq. (9). This gives the expression for the critical value of the control parameter $k_{\mathrm{c}}$,

$$
k_{\mathrm{c}}^{2}=\Omega^{2}+\gamma^{2},
$$

and for the critical value of the prediction time $\tau_{\mathrm{c}}$,

$$
\tau_{\mathrm{c}}=\frac{\operatorname{arctg}(\Omega / \gamma)+\pi}{\Omega+\omega} .
$$

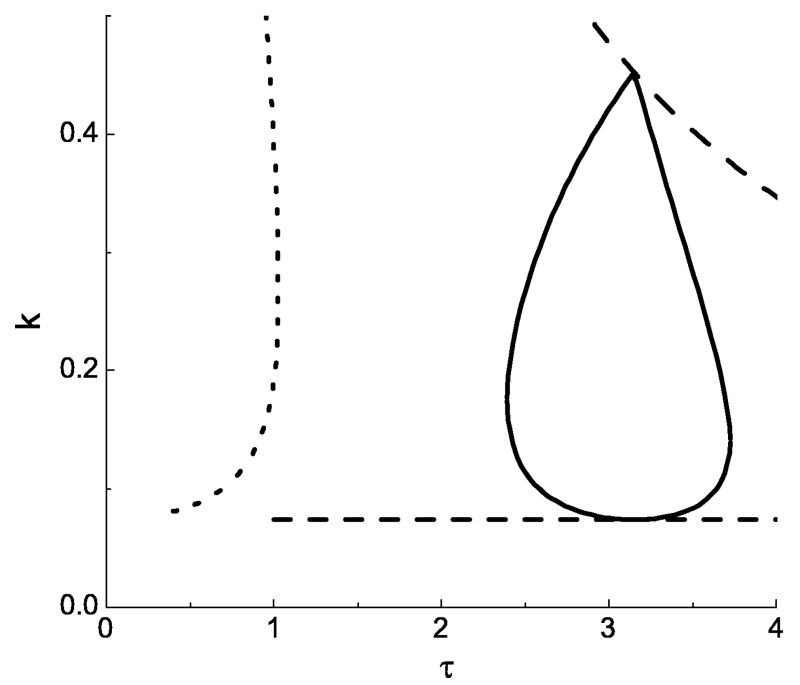

Fig. 2. Anticipating synchronization stability diagrams in the $\tau-k$ plane for coupled spirals at $\omega=0.997$ and $\gamma=0.074$. The dotted line bounds the region of the stability for diagonal coupling ( $\alpha=$ $0)$. The boundaries of stability for the PLCC $(\alpha=\omega \tau)$ are depicted by the dashed lines. The solid line confines the region of stability of the synchronization manifold for the anti-phase diagonal coupling (APDC, $\alpha=\pi$ ).

Making use of Eq. (15) we plotted the anticipating synchronization region in the $(\tau, k)$ plane for the anti-phase coupling $(\alpha=\pi)$ in Fig. 2, solid lines, and compared it with the stability regions for the PLCC $(\alpha=\omega \tau)$ [23], dash lines, and diagonal coupling $(\alpha=0)$, dot lines. We see that synchronization regime is possible for $\tau=$ 3.6, as it was obtained via the PLCC method [23]. Additionally, we depict a dependence of the eigenvalues $\operatorname{Re}(\lambda)$ versus coupling strength parameter $k$ for prediction time $\tau=3.6$ making use of Eq. (10) (Fig. 3). The minimum of this curve lies in the region of negative values of the eigenvalues when coupling parameter $k=k_{\mathrm{op}}=0.15$.

\section{The forecasting of chaotic dynamics}

The obtained analytical results encourage us to proceed with the forecasting of chaotic dynamics via anticipating synchronization with the APDC. We consider two unidirectionally coupled identical dynamical systems:

$$
\begin{aligned}
& \dot{\mathbf{r}}_{1}=\mathbf{f}\left(\mathbf{r}_{1}\right), \\
& \dot{\mathbf{r}}_{2}=\mathbf{f}\left(\mathbf{r}_{2}\right)+\mathbf{K}^{-}\left[\mathbf{r}_{1}-\mathbf{r}_{2}(t-\tau)\right],
\end{aligned}
$$

where the anti-phase diagonal coupling matrix $\mathbf{K}^{-}=$ $-\operatorname{diag}[1,1,1]$ is introduced in contrast to commonly 


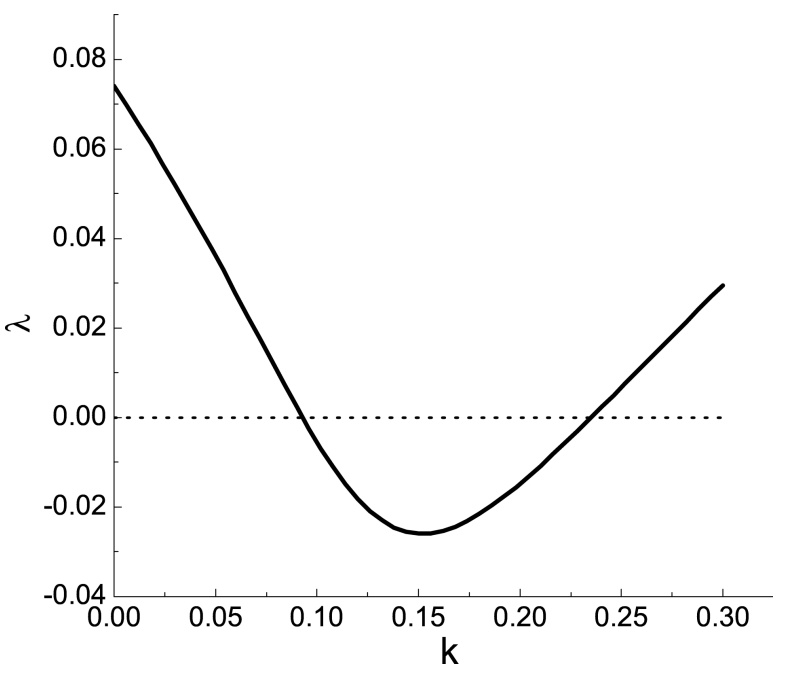

Fig. 3. Dependence of $\operatorname{Re}(\lambda)$ on coupling strength $k$ for coupled spirals with the parameters $\omega=0.997$ and $\gamma=0.074$. Prediction time equals to 3.6. Optimal value of the coupling parameter $k_{\mathrm{op}}=$ 0.15 .

used diagonal coupling matrix $\mathbf{K}=\operatorname{diag}[1,1,1]$. In the case of anticipating synchronization we have

$$
\mathbf{r}_{1}(t)=\mathbf{r}_{2}(t-\tau),
$$

and the coupling term $\mathbf{K}^{-}\left[\mathbf{r}_{1}-\mathbf{r}_{2}(t-\tau)\right]$ vanishes. In order to analyse the stability of the synchronization state we derive the dynamical equation

$$
\delta \dot{\mathbf{r}}_{2}=\left.\frac{\partial f}{\partial r_{2}}\right|_{\mathbf{r}_{2}(t)=\mathbf{r}_{1}(t+\tau)} \delta \mathbf{r}_{2}-\mathbf{K}^{-} \delta \mathbf{r}_{2}(t-\tau)
$$

for the deviation vector

$$
\delta \mathbf{r}_{2}(t)=\mathbf{r}_{2}(t)-\mathbf{r}_{1}(t+\tau) .
$$

To specify our investigation we restrict ourselves to the Rössler system [24]

$$
\dot{\mathbf{r}}=\mathbf{f}(\mathbf{r})
$$

with vector variable $\mathbf{r}=[x, y, z]$ and vector field

$$
\mathbf{f}(\mathbf{r})=[-y-z, x+a y, b+z(x-c)],
$$

where $a, b$, and $c$ are positive parameters, and both $\mathbf{r}$ and $\mathbf{f}$ are the vector columns. The phase portrait of the Rössler system is given in Fig. 4. Here the strange attractor is originated from the fixed point $\mathbf{r}_{0}=[(c-$ $s) / 2,(s-c) / 2 a,(c-s) / 2 a]$ located close to the origin, where $s=\left(c^{2}-4 a b\right)^{1 / 2}$. The fixed point is a saddle focus with an unstable two-dimensional manifold (an unstable spiral) almost coinciding with the $(x, y)$ plane and a stable one-dimensional manifold almost coinciding with the $z$ axis. The phase point of the system spends most time in the $(x, y)$ plane moving along the unstable spiral. Whenever $x$ approaches a value $x \approx c$,

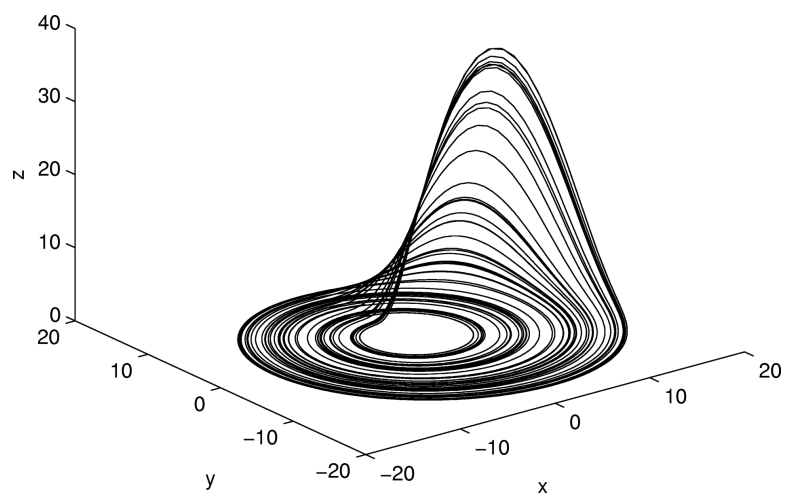

Fig. 4. Phase portrait of the Rössler system for $a=0.15, b=0.2$, and $c=10$.

the $z$ variable comes into play. The phase point leaves for a short time the $(x, y)$ plane and then returns to the origin via a stable $z$ axis manifold.

We proceed with the investigation of the two coupled Rössler [24] systems. That is, in Eqs. (16) we set $\mathbf{r}_{1}=\left[x_{1}, x_{2}, x_{3}\right]$ and $\mathbf{r}_{2}=\left[y_{1}, y_{2}, y_{3}\right]$ and in Eq. (21) we set such values of the parameters: $a=0.15$, $b=0.2$, and $c=10$. Dynamical equation (18) for the deviation of the slave system with the dynamical variable $\mathbf{r}_{2}=\left[y_{1}, y_{2}, y_{3}\right]$ transforms to

$$
\begin{aligned}
& \delta \dot{y}_{1}=\quad-\delta y_{2}-\delta y_{3} \\
& \delta \dot{y}_{2}=\quad \delta y_{1}+a \delta y_{2} \\
& \delta \dot{y}_{3}=\left[y_{1}(t+\tau)-c\right] \delta y_{3}+y_{3}(t+\tau) \delta y_{1}
\end{aligned}
$$

$$
+\mathbf{K}\left(\begin{array}{c}
\delta y_{1}(t-\tau) \\
\delta y_{2}(t-\tau) \\
\delta y_{3}(t-\tau)
\end{array}\right)
$$

where $\delta \mathbf{r}_{2}(t)=\mathbf{r}_{2}(t)-\mathbf{r}_{1}(t+\tau)=\left[\delta y_{1}, \delta y_{2}, \delta y_{3}\right]$.

The negative value of the maximal Lyapunov exponent is the essential condition for the synchronization regime to be stable. Making use of Eq. (22) we obtained the value -0.017 for the largest Lyapunov exponent of the slave for the value of the coupling strength $k$ equal to 0.17 (optimal) and the prediction time equal to 3.6. Numerical simulations of dynamics of two coupled Rössler systems demonstrating anticipating synchronization at specified system parameters are shown in Fig. 5.

In order to further simplify the coupling scheme and make it more attractive for experimental implementa- 


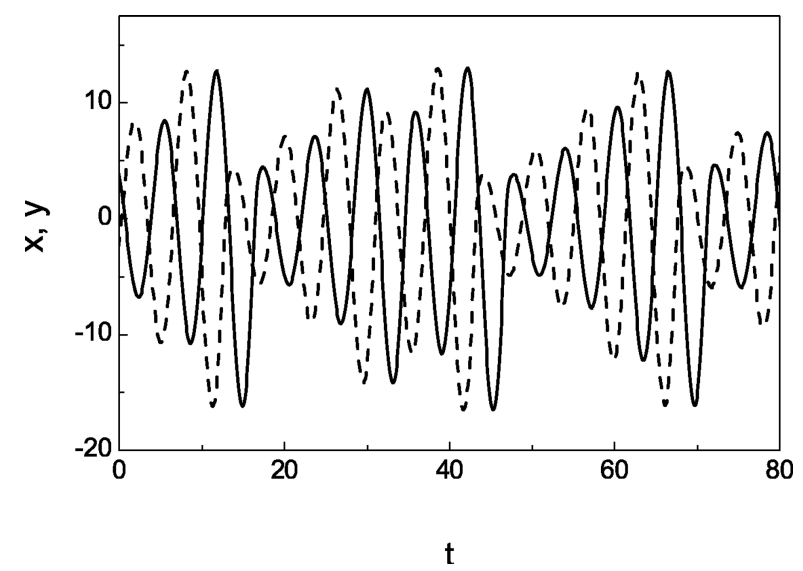

Fig. 5. Dynamics of the Rössler systems in the anticipating synchronization regime. The prediction time is $\tau=3.6$ and the coupling strength is $k=0.17$. System parameters are: $a=0.15, b=0.2$, and $c=10$.

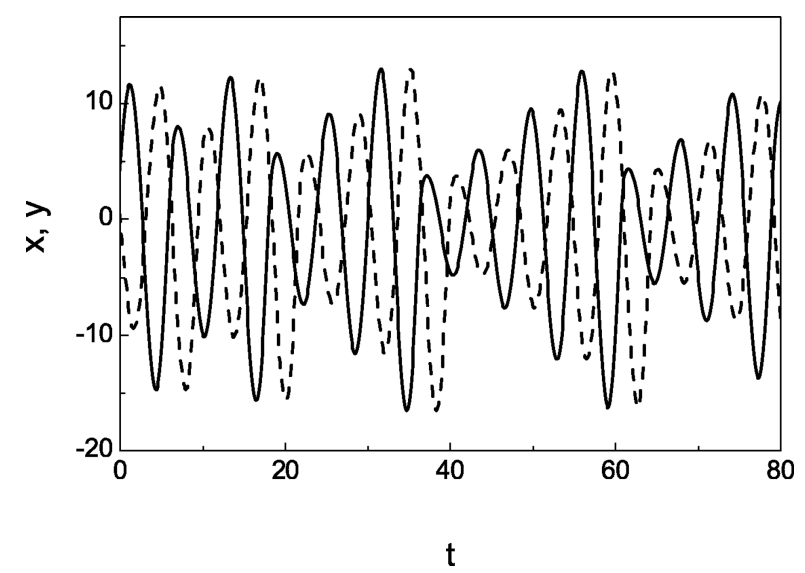

Fig. 6. Dynamics of the Rössler systems in synchronization regime with anti-phase coupling in $x$ axis direction. The prediction time is $\tau=3.6$ and the coupling strength is $k=0.3$. System parameters are: $a=0.15, b=0.2$, and $c=10$.

tion, we consider the coupling law $\mathbf{K}^{x}=\operatorname{diag}[1,0,0]$ in the scheme (16):

$$
\begin{aligned}
& \dot{\mathbf{r}}_{1}=\mathbf{f}\left(\mathbf{r}_{1}\right), \\
& \dot{\mathbf{r}}_{2}=\mathbf{f}\left(\mathbf{r}_{2}\right)+\mathbf{K}^{x}\left(\mathbf{r}_{1}-\mathbf{r}_{2}(t-\tau)\right) .
\end{aligned}
$$

Here we introduce the coupling only in one, $x$, variable. Numerical simulations of dynamics of two coupled Rössler systems in such a case are demonstrated in Fig. 6. We observe again the anticipating synchronization with the prediction time $\tau=3.6$. The negative value $(-0.01)$ of the maximal Lyapunov exponent confirms the stability of this regime.

\section{Conclusions}

Anticipating synchronization can be used as an effective tool for a long-time forecasting of chaotic dynamics in real time. We constructed a new coupling scheme in order to simplify the experimental implementation of the earlier introduced phase lag compensating coupling (PLCC) scheme [23]. The anti-phase diagonal coupling (APDC) scheme and the one-variable APDC were introduced. Performed analytical treatment and numerical simulations demonstrate that the attained prediction time with these coupling schemes is equal to the half of characteristic period of chaotic oscillations. The proposed APDC scheme has an obvious advantage of a simple experimental implementation in comparison to the PLCC algorithm.

\section{Acknowledgement}

We acknowledge the support from the global grant No VP1-3.1-ŠMM-07-K-01-025 "The development of chaos control and synchronization algorithms and their application to complex neural networks".

\section{References}

[1] E.N. Lorenz, Deterministic nonperiodic flow, J. Atmos. Sci. 20, 130-141 (1963).

[2] Handbook of Chaos Control, ed. H.G. Schuster (Wiley-VCH, 1998).

[3] H.U. Voss, Anticipating chaotic synchronization, Phys. Rev. E 61, 5115-5119 (2000).

[4] A. Pikovsky, M. Rosemblum, and J. Kurths, Synchronization: A Universal Concept In Nonlinear Sciences, Cambridge Nonlinear Science Series 12 (Cambridge University Press, Cambridge, England, 2001).

[5] V.S. Afraimovich, N.N. Verichev, and M.I. Rabinovich, Stochastically synchronized oscillations in dissipative systems, Izv. Vyssh. Uchebn. Zaved. Radiofiz. [Sov. Radiophys.] 29, 1050-1060 (1986) [in Russian].

[6] L.M. Pecora and T.L. Carroll, Synchronization in chaotic systems, Phys. Rev. Lett. 64, 821-824 (1990).

[7] S. Boccaletti, J. Kurths, G. Osipov, D.L. Valladares, and C.S. Zhou, The synchronization of chaotic systems, Phys. Rep. 366, 1-101 (2002).

[8] N.F. Rulkov, M.M. Sushchik, L.S. Tsimring, and H.D.I. Abarbanel, Generalized synchronization of chaos in directionally coupled chaotic systems. Phys. Rev. E 51, 980-994 (1995).

[9] R. Mainieri and J. Rehacek, Projective synchronization in three-dimensional chaotic systems, Phys. Rev. Lett. 82, 3042-3045 (1999). 
[10] M.G. Rosenblum, A.S. Pikovsky, and J. Kurths, Phase synchronization of chaotic oscillators, Phys. Rev. Lett. 76, 1804-1807 (1996).

[11] M.G. Rosenblum, A.S. Pikovsky, and J. Kurths, From phase to lag synchronization in coupled chaotic oscillators, Phys. Rev. Lett. 78, 4193-4196 (1997).

[12] C. Masoller, Anticipation in the synchronization of chaotic semiconductor lasers with optical feedback, Phys. Rev. Lett. 86, 2782-2785 (2001).

[13] S. Tang and J.M. Liu, Experimental verification of anticipated and retarded synchronization in chaotic semiconductor lasers, Phys. Rev. Lett. 90, 194101-1-4 (2003).

[14] S. Sivaprakasam, E. M. Shahverdiev, P.S. Spencer, and K.A. Shore, Experimental demonstration of anticipating synchronization in chaotic semiconductor lasers with optical feedback, Phys. Rev. Lett. 87, 154101-1-3 (2001).

[15] H.U. Voss, Real-time anticipating of chaotic states of an electronic circuit, Int. J. Bifurc. Chaos Appl. Sci. Eng. 12, 1619-1625 (2002).

[16] M. Ciszak, F. Marino, R. Toral, and S. Balle, Dynamical mechanism of anticipating synchronization in excitable systems, Phys. Rev. Lett. 93, 114102-1-4 (2004).

[17] M. Kostur, P. Hänggi, P. Talkner, and J.L. Mateos, Anticipated synchronization in coupled inertial ratchets with time-delayed feedback: A numerical study, Phys. Rev. E 72, 036210-1-6 (2005).

[18] M. Ciszak, O. Calvo, C. Masoller, C.R. Mirasso, and R. Toral, Anticipating the response of excitable systems driven by random forcing, Phys. Rev. Lett. 90, 204102$1-4$ (2003).

[19] M. Ciszak, J.M. Gutiérrez, A.S. Cofino, C. Mirasso, R. Toral, L. Pesquera, and S. Ortin, Approach to predictability via anticipated synchronization, Phys. Rev. E 72, 046218-1-8 (2005).

[20] O. Calvo, D.R. Chialvo, V.M. Eguíluz, C. Mirasso, and R. Toral, Anticipated synchronization: A metaphorical linear view, Chaos 14, 7-13 (2004).

[21] H.U. Voss, Dynamic long-term anticipation of chaotic states, Phys. Rev. Lett. 87, 014102-1-4 (2001).

[22] C. Mendoza, S. Boccaletti, and A. Politi, Convective instabilities of synchronization manifolds in spatially extended systems, Phys. Rev. E 69, 047202-1-4 (2004).

[23] K. Pyragas and T. Pyragiené, Coupling design for a long-term anticipating synchronization of chaos, Phys. Rev. E 78, 046217-1-4 (2008).

[24] O.E. Rössler, An equation for continuous chaos, Phys. Lett. A 57, 397-398 (1976).

[25] R.M. Corless, G.H. Gonnet, D.E.G. Hare, D.J. Jeffrey, and D.E. Knuth, On the Lambert $W$ function, Adv. Comput. Math. 5, 329 (1996).

\title{
CHAOTINIŲ BŪSENŲ PROGNOZĖ NAUDOJANT PRIEŠINGOS FAZĖS RYŠI
}

\author{
T. Pyragienè, K. Pyragas \\ Fiziniu ir technologijos mokslu centro Puslaidininkiu fizikos institutas, Vilnius, Lietuva
}

\section{Santrauka}

Nagrinejama prognozuojanti sinchronizacija [3]. Toks sinchronizacijos režimas stebimas siųstuvo-imtuvo konfigūracijoje, kai siųstuvas veikia imtuvą, o atvirkštinio ryšio nèra. Imtuvas sinchronizuojasi su siųstuvu ateitimi, t. y. imtuvas numato siųstuvo dinamikos ateitị. Chaotinių sistemų prognozès uždaviniuose siekiama gauti kiek įmanoma ilgesnę prognozės trukmę. Atlikti tyrimai parodè, kad paprastai naudojama diagonali matrica yra neefektyvi [3], nes šiuo atveju maksimali prognozės trukmé žymiai mažesnè už būdingąsias dinaminès sistemos trukmes. Neseniai pasiūlème nedia- gonalią ryšio matricą, kurios konstravimo algoritmas paremtas fazès delsos kompensacija (FDK) imtuvo sistemoje [23]. Šis metodas žymiai prailgina prognozès trukmę tiek, kad ji tampa palyginama su būdinguoju chaotinès sistemos periodu.

Darbe siūlomas modifikuotas FDK algoritmas: imtuvo sistemoje uždelstas grižtamasis ryšys ijungiamas priešfazejje. Ši modifikacija žymiai supaprastina prognozuojančios sinchronizacijos režimo eksperimentini igyvendinimą. Pasiūlyto algoritmo atveju prognozės trukmė yra lygi charakteringo chaotinès sistemos periodo pusei. 